\title{
Distopia e utopia na obra de David Simon: uma leitura de The Plot Against America
}

André Carvalho ${ }^{a}$ (1)

\section{RESUMO}

O objetivo principal deste artigo é discutir os elementos distópicos e utópicos presentes nas séries televisivas escritas ou produzidas por David Simon, como The Wire e Show me a Hero, com especial atenção à análise de The Plot Against America, adaptação recente realizada por David Simon e Ed Burns do romance homônimo de Philip Roth, que narra uma "história alternativa" em que os Estados Unidos elegem Charles Lindbergh como presidente e aliam-se às forças do Eixo na Segunda Guerra Mundial. Em primeiro lugar, estabelecemos a centralidade do conceito de distopia no debate político contemporâneo a partir da eleição de Donald Trump em 2016. Identificamos que o termo desponta subliminarmente no discurso de vitória da vice-presidenta eleita, Kamala Harris, representando a tendência apontada por Jill Lepore (2017) de aumento da polarização política. Em seguida, examinamos as discussões contemporâneas sobre a distopia, o que nos

Recebido em: 30/11/2020 Aceito em: 20/01/2021

\footnotetext{
${ }^{a}$ Universidade Federal de Santa Catarina, Programa de Pós-Graduação em Inglês, Florianópolis, SC, Brasil. E-mail: carvalhoandre@outlook.com
} 


\begin{abstract}
ajudará a fazer um levantamento, nas demais séries de David Simon, também de seus elementos utópicos, cujos limites temáticos e formais se revelam exemplares de uma classe política alinhada ao Partido Democrata. Argumentamos que Simon se apoia em uma utopia do trabalho, da social-democracia e da família, e que cada um desses elementos se conjuga tanto às convenções do formato do seriado televisivo dramático contemporâneo quanto às transformações políticas do período pósfordista e neoliberal a partir do final dos anos 1970.
\end{abstract}

Palavras-chave: Distopia. Utopia. Televisão. Literatura. Democracia.
1 "a clear message [...]

hope, unity, decency, science, and yes, truth." Todas as traduções de textos em idioma estrangeiro são próprias, a menos que explicitamente indicado na bibliografia.

\section{A breve distopia de Trump}

O discurso de vitória de Kamala Harris, a primeira mulher negra eleita vice-presidenta dos Estados Unidos, representou o clímax de uma sensação compartilhada não só pelos apoiadores do Partido Democrata, mas por todos aqueles que sentiam repulsa ao ver Donald Trump no mais alto cargo de autoridade do país. Quatro anos antes, o mundo se perguntava: como isso foi possível? Qual foi a artimanha desse empresário de reputação duvidável, um apresentador de reality shows, para subverter o sistema político de uma nação que, até aquele momento, não tinha dúvidas em se autodeclarar a mais longeva democracia do mundo? $\mathrm{O}$ discurso de Harris pauta-se na teoria de que em 2016 se teria iniciado um hiato, um estado de exceção que finalmente se encerrava nas eleições de 2020. O voto em Joe Biden seria "uma mensagem clara: [...] de esperança, unidade, decência, ciência e, sim, verdade" (HARRIS, 2020, n. p. $)^{1}$. Entendemos que Trump representaria o oposto: desesperança, desunião, indecência, recusa da ciência. A ênfase no último termo, "verdade", depende da pausa antes e depois do "sim": Trump estaria no campo da mentira, das fake news, da negação da realidade em nome de "fatos alternativos", enquanto a verdade do caráter de Biden, da democracia estadunidense e da ciência seria autoevidente. No discurso, Harris consolidou a noção de que os Estados Unidos viveram, 
2 "the 'failed utopia' of twentieth-century totalitarianism."

3 "to denounce and to warn against Utopian programs in the political realm." durante a presidência de Trump e a primeira onda da pandemia de COVID-19, uma breve distopia, um interlúdio ou percalço no caminho do progresso. Agora, os negócios poderiam seguir normalmente.

A palavra distopia é registrada pela primeira vez na língua inglesa em 1747, mas só ganha uso corrente a partir da segunda metade do século XX (SARGENT, 2010, p. 4). O significado imediato ainda mantém relação direta com a etimologia: antes de mais nada, denota um "lugar ruim". Contudo, popularizada no contexto da Segunda Guerra Mundial e da Guerra Fria, a distopia, como fenômeno histórico e literário, tem raízes nas experiências da "'utopia fracassada' do totalitarismo do século XX"2 (CLAEYS, 2017, p. 4). Os romances 1984 (ORWELL, 1987) e Brave New World (HUXLEY, 1947), apesar de não serem os primeiros com características distópicas, são frequentemente citados como os modelos mais influentes do gênero. Em ambos, o mundo representado pressupõe uma organização total e planejada da sociedade que acaba gerando o efeito inverso ao esperado. Em vez da conquista plena da felicidade (utopia), produz-se o inferno na Terra. Para Jameson (2005, p. 142), essa tradição literária é mais propriamente antiutópica, uma vez que "denuncia e adverte contra programas utópicos no campo político"3 (JAMESON, 2005, p. 198-199). A distopia, nesse sentido, não simplesmente representa um lugar ruim, mas propõe a inevitabilidade do desastre caso se ouse enveredar para um lugar melhor. Ela seria um gênero essencialmente conformista ou reacionário.

Visto por essa perspectiva, o discurso de Harris, embora repleto de esperança e renovação, atualizaria o impulso antiutópico. Ele aniquila o slogan Make America Great Again (Tornar a América grandiosa novamente), pois fica subentendido que o país nunca deixou de ser grandioso, exceto pelo breve hiato de quatro anos.

O principal procedimento retórico da antiutopia é o mesmo, independentemente da orientação política de quem a produz: basta exagerar um traço do oponente e estender as consequências até que revelem seu negativo. Republicanos desconfiam daquilo que consideram utópico na agenda política democrata, sobretudo as metas de justiça racial/sexual/social/ ecológica que têm mobilizado a parcela mais jovem, mais conectada e mais urbana de eleitores. Para a direita, planejar a 
4 "Em sua definição moderna, uma distopia pode ser apocalíptica ou pós-apocalíptica, ou nenhuma das duas, mas ela tem que ser antiutópica, uma utopia virada de cabeça para baixo, um mundo em que as pessoas tentaram produzir uma república da perfeição, apenas para descobrir que criaram uma república de sofrimento." (LEPORE, 2017, $\mathrm{n}$.

p.) "In its modern definition, a dystopia can be apocalyptic, or post-apocalyptic, or neither, but it has to be anti-utopian, a utopia turned upside down, a world in which people tried to build a republic of perfection only to find that they had created a republic of misery."

5 "despair [...] asking only that you enjoy the company of people whose fear of the future aligns comfortably with your own."

6 "epistemological abyss" justiça por meio de políticas de Estado seria o primeiro degrau em direção ao stalinismo. Para a esquerda, o apego a valores tradicionais da direita inevitavelmente se degeneraria em milícias terraplanistas.

Jill Lepore (2017), que também subscreve à definição de distopia como antiutopia, ${ }^{4}$ denuncia a função retrógrada da ficção distópica recente em uma situação política altamente polarizada. Para a autora, particularmente romances distópicos infanto-juvenis ajudariam a confirmar os vieses que têm perpassado a dificuldade de comunicação entre campos políticos antagônicos. Ao imaginar futuros piores, a distopia encorajaria o "desespero [...], pedindo apenas que você desfrute da companhia de pessoas cujo medo do futuro se alinhe confortavelmente com o seu" ${ }^{\prime \prime}$ (LEPORE, 2017, n. p.). A observação de Lepore incorpora-se ao tema geral de seus últimos escritos, em particular o abrangente volume de história dos Estados Unidos, These Truths (2018), em que a autora examina, desde Cristóvão Colombo até o início do governo Trump, diversos instrumentos linguísticos, econômicos, políticos e tecnológicos que teriam culminado na enorme polarização que vemos nestas primeiras décadas do século XXI. Ela traz à luz a gênese de polêmicas, como o direito ao aborto e ao porte de armas, mostrando que, antes dos anos 1970, esses temas estavam desassociados de linhas partidárias (LEPORE, 2018, p. 647-691). Contudo, a partir das crises econômicas e do avanço de estratégias populistas e midiáticas na política, cada partido passou a incorporar panfletos acerca de assuntos polêmicos com a intenção de marcar território em uma guerra cultural de costumes, e qualquer tentativa de discussão liberal esclarecida foi dificultada ou interrompida. Hoje, isso parece ser mais evidente do que nunca, conforme assistimos a questões de saúde pública mais banais, como o uso de máscaras de proteção durante uma pandemia, se tornarem distintivos de filiação política. A distopia, então, para Lepore, seria mais um fator a contribuir para o recrudescimento das barreiras de comunicação, para o desmoronamento do diálogo político e para fissuras na própria cognição - o que a autora chama de "abismo epistemológico"6 (LEPORE, 2018, p. 711). Fiç̧ões distópicas conformariam os indivíduos de cada partido em seus rincões ideológicos, não por meio da afirmação da imaginação, dos desejos e dos sonhos (campo da utopia), mas 
7 "On one hand, utopia has been absorbed into the affirmative ideologies of the totalizing systems of Stalinist Russia,

Nazi Germany, and the corporate United States.

[...] in dystopia [...] utopian figures of hope were transmuted into an attack on present social systems which claim to be already existing utopias. [...] Unfortunately, the dystopian narrative itself has all too easily been recruited into the ideological attack on authentic utopian expression: commentators cite the dystopia as a sign of the very failure of utopia and consequently urge uneasy readers to settle for what is and cease their frustrating dreams of a better life." pela via do medo. Elas denegariam a possibilidade de um mundo alternativo - o mundo do outro, ou o mundo do futuro - em nome do mundo do mesmo, no presente.

Tom Moylan (2014, p. 7-9) reforça a relação entre utopias, distopias e guerra ideológica:

Por um lado, a utopia foi absorvida pelas ideologias afirmativas de sistemas totalizantes da Rússia stalinista, da Alemanha nazista e dos Estados Unidos corporativistas [...] na distopia [...] figuras utópicas de esperança foram transmutadas em um ataque a sistemas sociais existentes que alegam ser utopias concretizadas. [...] Infelizmente, a própria narrativa distópica foi facilmente recrutada a se tornar um ataque ideológico à expressão utópica autêntica: comentadores citam a distopia como um sinal da própria falência da utopia e, consequentemente, incitam leitores temerosos a se conformarem com o que existe e a abandonar seus sonhos frustrados de uma vida melhor. (grifos nossos) ${ }^{7}$

A distopia de um partido ou de uma nação denuncia a utopia do outro. Ela desmascara a falsa asserção de que o sistema antagônico tenha alcançado o paraíso terrestre. Por consequência, a garantia de superar uma distopia, como no discurso de Harris, devolve-nos à terra prometida. Após vencer o inimigo que nos meteu em uma distopia, retornamos ao caminho do bem.

\section{A breve distopia de Lindbergh}

Troquemos Donald Trump por Charles Lindbergh, 2016 por 1940, a realidade pela ficção. O enredo de The Plot Against America, tanto o romance original de Philip Roth (2005) quanto a série de David Simon e Ed Burns (2020), segue de perto os temas abordados por Kamala Harris: a democracia está ameaçada por uma alternativa distópica; cabe aos defensores da República corrigir o curso da história. As eleições de 1940 são vistas a partir da perspectiva de uma família judia de New Jersey, que assiste a Charles Lindbergh, o famoso aviador, concorrer contra Frank Delano Roosevelt e ganhar, avançando uma plataforma que vai da não intervenção na Guerra à colaboração aberta com o regime nazista alemão.

Vale lembrar que o lema America First (América em primeiro lugar) foi o slogan de um movimento encabeçado pelo Lindbergh real e por Henry Ford para manter o 
8 "The America First Committee is true Americanism and true patriotism."

${ }^{9}$ O livro mais abrangente sobre o assunto é de Wallace (2003), que corrobora essas afirmações com evidências de documentos do governo.

${ }^{10}$ Considerando o estado de incerteza que nos encontramos durante a escrita deste artigo, quando Donald Trump vive sua própria realidade alternativa e busca manipular o sistema eleitoral para reverter o resultado desfavorável, a série supera $o$ romance na capacidade de traduzir o momento atual.

11 "We seemed to be becoming more inclusive, less susceptible to demagogue-ary (sic)."

12 Em outra entrevista: "[O romance de Roth] parecia um antigo artefato, já que o país estava caminhando em uma direção mais inclusiva e nós estávamos menos suscetíveis a sentir medo do outro." (SIMON, 2020b, n. p.). "[Roth's novel] just felt like an artifact, with the country moving in a more inclusive direction and we were less susceptible to fears of the other."

13 "[Os produtores] estavam falando sobre as eleições e o que qualquer um de nós deveria tentar fazer que dialogasse com o momento político [...]"

"They were talking about the election and what anybody should try to make that could speak to the political moment [...]" (SIMON, 2020b, n. p.).

14 "one of the most fundamental dates of our history." isolacionismo no começo da Segunda Guerra Mundial. Assim como representado na ficção de Roth, Simon e Burns, ambos simpatizavam com o regime nazista e expunham abertamente ideais eugenistas, antissemitas e supremacistas brancos. $\mathrm{O}$ comitê America First que fundaram inclusive ganhou elogios do governo nazista: "'é isso que significa americanismo, verdadeiro patriotismo'"'8 (LEPORE, 2018, p. 481-482, citando o Ministro de Propaganda de Berlim). ${ }^{9}$

Na ficção, judeus estadunidenses passam a ser abertamente perseguidos e sofrem sua própria versão da Noite dos Cristais, até o ponto, no final das obras, em que o avião pilotado por Lindbergh desaparece e ele é dado por morto. Aqui, romance e série divergem: Roth narra a vitória de Roosevelt na eleição seguinte, sua intervenção na Europa e no Pacífico, e o retorno à história oficial, com a vitória sobre o nazismo e a continuação da democracia republicana liberal. Simon e Burns, ao contrário, encerram as últimas cenas da série antes de o resultado ser anunciado. O final feliz fica em suspenso e a dúvida é reiterada por meio de uma montagem que exibe votos sendo queimados, o que sugere fraude eleitoral. ${ }^{10}$

David Simon conta que ao ser abordado pela primeira vez em 2013 por um produtor de televisão para adaptar o livro de Roth, ele recusou, acreditando que, logo após a eleição de Barack Obama, "nós parecíamos estar nos tornando mais inclusivos, menos suscetíveis à demagogia"11 (SIMON, 2020c, n. p.). ${ }^{12}$ Contudo, em 2016, foi o momento político que estimulou produtores da $\mathrm{HBO}$ a buscarem ativamente algo que se adequasse à nova realidade de Trump, e Simon recrutou apoio para adaptar o romance em uma minissérie. ${ }^{13}$ A intenção explícita era a de alertar para o risco que Trump representava à democracia: a ideia para o projeto tomou forma quando ele assumiu o governo, e a série estreou nos meses que antecederam o pleito de 2020, numa eleição que o próprio Simon chamou de "uma das datas mais fundamentais da nossa história"14 (2020c, n. p.). Sem dúvida, as intenções militantes de Simon estão expressas; ${ }^{15}$ resta voltar à questão sobre a utilização do instrumento da distopia para esse fim.

Os argumentos de Lepore (2017), além dos pontos levantados por críticos como Jameson (2005), Moylan (2014) e Williams $(1978,1983,2010)$, têm em comum a desconfiança perante a distopia, compreendida como antiutopia. Como 
15 "A única razão de gastar dinheiro para filmar [a série] é que esta geração está enfrentando uma ameaça fundamental às normas de nossa república e ao autogoverno." "The only reason to spend the money to film [this show] is that this generation is facing a fundamental threat to the norms of our republic and selfgovernance." (SIMON, 2020a). Ainda: "Acho que vivemos em uma democracia que está sendo sabotada. [...].

Mas eu acho que até as normas democráticas mais básicas que existem em nossa forma republicana de governo estão sendo demolidas com uma velocidade assombrosa." "I think we live in a democracy that is being undercut.

[...] But I think even our basic democratic norms that exist within our republican form of governance are being demolished with a rapidity that is startling." (SIMON, 2020d).

16 "as an insatiable and lucid hunger for power and its exercise"

17 "essentially 'bourgeois' in character and prompted by hostility to the idea of a workers' state" vimos, Lepore e Moylan destacam o conformismo: apontar o negativo em uma realidade alternativa, seja no futuro, seja em outro planeta/universo, por comparação, acaba por ressaltar o que há de positivo no presente, na conjuntura imediata, na realidade concreta do público leitor/espectador. $O$ par binário é reforçado pelo esquematismo. Jameson (2005, p. 200), tratando de 1984, sugere que distopias envolvem uma concepção essencialmente negativa da natureza humana, "como uma fome lúcida e insaciável por poder e seu exercício"16. Dessa perspectiva, segundo Jameson, os romances distópicos pressupõem a degeneração da utopia, porque consideram natural ao ser humano abusar do poder; toda mudança planejada implicaria concentração e uso exagerado de força. Em outras palavras, essa visão de natureza humana preclude qualquer esforço coordenado que ultrapasse os limites de pequenas reformas locais.

\section{Anti-antiutópicos}

Andrew Milner (2012) coloca-se enfaticamente contra a posição dos "anti-antiutópicos", como Suvin $(1977,2010)$, Williams (1978, 1983, 2010), Freedman (2000) e, em especial, Jameson (2005), que é visto pelo autor (Milner, 2012, p. 2) como responsável por influenciar toda uma geração de críticos, como Moylan (2014), Wegner (2010) e outros. Milner (2012, p. 115) fala da "antipatia à distopia" e do "desgosto pela distopia", o que culminaria na leitura equivocada que Jameson supostamente faz de 1984, "não apenas radicalmente e excessivamente politizada, mas também diretamente em conflito com uma tradição que a maioria dos entusiastas da ficção científica considera central ao gênero" (MILNER, 2012, p. 2).

Segundo Milner (2012, p. 116), o argumento de Jameson, próximo ao de Williams (1983), consideraria 1984 "essencialmente 'burguês' em caráter, atiçado pela hostilidade à ideia de um estado dos trabalhadores"17, ao socialismo e ao Partido Trabalhista inglês. Como vimos, ao pintar um quadro essencialmente negativo de uma revolução que se corrompe em pesadelo, o romance indicaria, de acordo com a interpretação de Jameson e dos demais estudiosos, a impossibilidade de qualquer transformação - particularmente uma mudança que 
18 “[...] a perda da individualidade (burguesa) é um dos grandes temas antiutópicos." "[...] the loss of (bourgeois) individuality is certainly one of the great antiUtopian themes." (JAMESON, 2005, p. 7). De fato, a acepção de totalitarismo de

Orwell, Forster, Huxley e demais escritores de distopias mencionados ao longo deste trabalho parece depender exclusivamente da noção de liberdade individual de expressão. Alguns ensaios de Orwell (2003b, 2003a) e Forster (1966) revelam a grande ênfase que eles conferem à liberdade de imprensa e ao ideal do escritor autônomo livre. Infelizmente, não há espaço aqui para discutir com profundidade as armadilhas dessa acepção, mas os paralelos com a posição de Simon deverão ficar claros na última seção do artigo.

${ }^{19}$ Em uma carta escrita ao diretor do sindicato automotivo inglês, Orwell explica: "Meu recente romance $\mathrm{NÃO}$ se propõe como um ataque ao Socialismo nem ao Partido

Trabalhista inglês (que apoio), mas como uma demonstração [show$u p$ ] das perversões a que está suscetível uma economia centralizada que já se realizaram parcialmente pelo Comunismo e pelo

Fascismo. Eu não acredito que esse tipo de sociedade necessariamente acontecerá, mas acredito (considerando, claro, que o livro é uma sátira), que algo semelhante possa acontecer. Acredito que ideias totalitárias se enraizaram nas mentes de intelectuais em todo o mundo, e tentei estender as ameace o individualismo burguês-liberal do intelectual no regime totalitário do controle e da vigilância. ${ }^{18}$

Em seu primeiro contra-argumento Milner (2012, p. 117) afirma que a crítica de Orwell jamais se direcionou à ideia do socialismo ou ao Partido Trabalhista, e sim às perversões do stalinismo. ${ }^{19}$ Além disso, e mais relevante para nós, Milner defende que as leituras que Jameson e demais autores fazem de 1984 e de diversos outras outras obras, como The Handmaid's Tale (ATWOOD, 1986), não se atêm às evidências textuais em relação ao quadro narrativo. Em 1984, o final do romance não seria o "The End", mas sim o anexo sobre a novilíngua (Newspeak), que sugere a derrocada da sociedade distópica retratada pelo enredo e a sobrevivência de uma forma superior de organização social, o que teria permitido a redação do próprio relato e de seu apêndice acadêmico. Na obra de Atwood, a narrativa também é enquadrada retrospectivamente, indicando que os acontecimentos tenham ficado em um passado distante. Se a objeção dos críticos era ao retrato funesto que bloqueia a agência humana e induz ao conformismo, a atenção ao enfoque narrativo e ao modo condicional e subjuntivo (MILNER, 2012, p. 135) - isso pode(ria) acontecer se... - significa justamente o contrário: os romances marcam a importância da atuação política organizada diante das ameaças em potencial. Nesse sentido, 1984 e outras distopias estariam em pleno acordo com a intenção expressa de David Simon de produzir a série como um sinal de alerta, uma advertência:

Como cidadãos, este é o nosso momento. Este é nosso pivô histórico. O que acontecerá no próximo ano, ou no seguinte, vai afetar nosso futuro como uma República, se nossa República, de fato, tiver um futuro. É realmente fundamental. Democracia e liberdade, e a liberdade que a democracia fornece, nunca estão totalmente conquistadas. É uma luta diária. A cada dia, você tem que matar algumas cobras, e se você parar de matar as cobras, se você parar de exigir sua própria liberdade e seus direitos civis, eles vão desaparecer. ${ }^{20}$ (SIMON, 2020b, n. p.).

Reparemos que o chamado à ação e a concepção de democracia como uma conquista sempre constante também estão presentes no discurso de Harris (2020, n. p.): “A democracia da América não está garantida. Sua força depende 
consequências dessas ideias até o limite da lógica." "My recent novel is NOT intended as an attack on Socialism or on the British Labour Party (of which I am a supporter) but as a showup of the perversions to which a centralised economy is liable and which have already been partly realised in Communism and Fascism. I do not believe that the kind of society I describe necessarily mil arrive, but I believe (allowing of course for the fact that the book is a satire) that something resembling it could arrive. I believe also that totalitarian ideas have taken root in the minds of intellectuals everywhere, and I have tried to draw these ideas out to their logical consequences." (ORWELL, 1968, p. 502, maiúsculas do autor).

20 "That, as citizens, this is our moment. This is our historical pivot. What happens in the next year or two is gonna affect the future of our Republic, if our Republic does, indeed, have a future. It's that critical. Democracy and freedom, and the freedom that democracy provides, are never entirely won.

It's a daily struggle. Every day, you have to kill a few snakes, and if you stop killing snakes, and you stop demanding your own freedom and your own civil liberties, they disappear."

21 "America's democracy is not guaranteed. It is only as strong as our willingness to fight for it. To guard it, and never take it for granted."

\footnotetext{
22 "a warning to the reader that some thing must and, by implication, can be done in the present to avoid the future"

${ }^{23}$ E aprofundado em Moylan (2014), com a introdução da ideia de "utopia crítica".
}

da nossa vontade de lutar por ela. De protegê-la, e nunca a considerar garantida." ${ }^{21}$

Advertência é um termo caro à distopia. $\mathrm{O}$ texto basilar de Sargent, "The Three Faces of Utopianism Revisited", já definia o gênero como "uma advertência ao leitor de que alguma coisa deve e, por implicação, pode ser feita no presente para evitar o futuro"22 (SARGENT, 1994, p. 6). Nessa perspectiva, ao contrário de Lepore e outros críticos, a imaginação do pior cenário não alimentaria a paralisia nem o conformismo, mas indicaria caminhos alternativos para que a distopia não chegasse a acontecer. O condicional e o subjuntivo, ou o método da "extrapolação" (SARGENT, 1994, p. 8), estão presentes em Harris e Simon e na leitura atenta das distopias feita por Milner.

Neste ponto, vale introduzir o conceito de "distopia crítica". O termo, cunhado por Moylan (2000), ${ }^{23}$ é retomado por Jameson (2005, p. 198) como uma contraposição à "antiutopia". Como vimos, para Jameson, 1984 seria uma antiutopia, pois vetaria todo o potencial revolucionário ao equiparar centralização político-econômica ao totalitarismo e ao pintar um quadro negativo que não deixa margens à esperança. Distopias críticas, por outro lado, ainda conservariam um caráter utópico, qualificando e avaliando possibilidades, denunciando exageros e riscos, mas apresentando alternativas de ação. Entrariam aqui romances como The Dispossessed (LE GUIN, 2009) - representantes de uma tradição de ficção científica que desponta nos anos 1960-1970, quando se renovou a esperança na luta política pelos direitos civis -, além de romances satíricos, como Player Piano (VONNEGUT, 1952) já que a sátira é, por definição, crítica. Milner (2012, p. 118), corrigindo a leitura de Jameson, resgata 1984 e outros romances para o campo da distopia crítica, mostrando tanto o espaço utópico codificado no enquadramento narrativo, conforme discutido anteriormente, quanto a explicação do próprio Orwell de que sua obra seria uma sátira (consultar nota 20).

O valor do argumento de Milner (2012, p. 120) é que ele abre a possibilidade de investigar o "impulso utópico" nas distopias. Como veremos, nas obras anteriores de David Simon, já se articula um impulso utópico que continua em The Plot Against America. Nas próximas seções, identificaremos não apenas um alerta vago à ação, mas também o que de fato constitui os valores afirmativos, a ideia de uma vida mais 
${ }^{24}$ Uma análise da história desse tipo de série, que leva em conta Homicide e toda a obra de Simon, encontra-se em Carvalho (2018).

${ }^{25}$ Cf. Carvalho (2018, p. 259, nota 111) para uma discussão sobre a relação entre Balzac e The Wire.

26 "ceasing to replicate a static reality" justa, que vêm sendo articulados pelo trabalho do produtor. Investigações similares foram conduzidas pelo próprio Jameson, em seu Archaeologies of the Future (2005) e em diversos outros ensaios. O método original remonta a Ernst Bloch, cujo Princípio Esperança (2005) demonstra a capacidade de identificar a utopia em variados aspectos da cultura e do cotidiano.

\section{A utopia do trabalho}

A primeira obra televisiva de que Simon participou, Homicide: Life on the Street (1993-1999), foi baseada em seu próprio livro-reportagem, Homicide: A Year on the Killing Streets. (1991) sobre um departamento de homicídio da cidade de Baltimore. A série se pautava pelo modelo da narrativa procedural, típica da televisão estadunidense desde os anos $1980 .{ }^{24}$ As principais qualidades, tanto do livro quanto da série, residiam no realismo com que o ambiente da delegacia de polícia era representado e na atenção à caracterização das personagens. O trabalho de Simon, especialmente na reportagem, destaca-se, como indiciado no título da obra de Linda Williams (2011), pela sua "imaginação etnográfica": a capacidade de dramatizar as personalidades que habitavam o ambiente de trabalho, seus maneirismos e as dinâmicas das relações pessoais e profissionais. Reportagem e dramaturgia confluem também na segunda série em que Simon se envolve, The Corner (2000), baseada no livro homônimo escrito em conjunto com Ed Burns (SIMON; BURNS, 1998). Aqui, a perspectiva se inverte, e a atenção se volta não para o distrito policial, mas para os usuários de drogas e suas famílias nos bairros pobres de Baltimore. Simon e Burns, então, produzem The Wire (2002-2008), em que ambos os universos se juntam para criar uma narrativa balzaquiana ${ }^{25}$ de múltiplos núcleos com dois polos principais: o universo policial e o ecossistema dos guetos de Baltimore.

Jameson (2015, p. 246) identifica o impulso utópico em The Wire ao defender que a série supera a "replicação da realidade estática" ${ }^{26}$, graças ao mecanismo da investigação policial em equipe e às manifestações dos desejos de seus personagens, sobretudo de Frank Sobotka, o chefe do sindicato de estivadores na segunda temporada. Tanto a investigação quanto a luta de Sobotka pela reforma do porto de Baltimore, 
27 "deliberate processes of transformation"

28 "human projects, to the working out of utopian intention" que traria de volta os empregos perdidos ao longo das últimas décadas, para Jameson (2015, p. 246), são "processos deliberados de transformação" ${ }^{\prime 27}$ que sujeitam o conceito de sociedade a "projetos humanos, à realização da intenção utópica"28. Em outras palavras, The Wire conseguiria ser realista sem ser fatalista. A irracionalidade da burocracia, o engessamento da rotina policial e a força de gravidade das gangues de rua, a morte do trabalho perante o capital financeiro globalizado, as armadilhas do sistema educacional falido e da política corrompida, além da crise do jornalismo - elementos centrais dos roteiros de cada uma das cinco temporadas de The Wire - não encerram a atividade humana em um esquema determinista, mas encontram brechas e vias de ação inesperada que energizam o drama com a utopia de uma práxis possível, tanto no plano individual quanto no coletivo. Para Jameson, o próprio elemento detetivesco tão comum na cultura de massa televisiva e novelesca é subvertido ao não se enfatizar o gênio de investigadores particulares, mas a ação coordenada da equipe.

Em pesquisa anterior, apontamos como esse elemento utópico se conecta a narrativas que tematizam o mundo do trabalho (CARVALHO, 2018), obras que baseiam sua dramaturgia nos conflitos entre as pressões do capital e a ação criativa do trabalhador. Isso se estende a outras séries de David Simon, como Treme (2010 - 2013), que aborda o trabalho artístico, Generation Kill (2008), apresentando o serviço militar, e The Deuce (2017-2019), situada no universo do trabalho sexual.

Em The Plot Against America, embora a distopia seja localizada propriamente na esfera política, existe um foco de utopia trabalhadora incrustada no núcleo paralelo da empresa transportadora do irmão do protagonista. Em determinado momento, Herman Levin (Morgan Spector), o pai da família principal, demite-se do emprego de vendedor de apólices de seguro, resistindo à realocação de judeus arquitetada pelo governo de Lindbergh. Então, ele é empregado por seu irmão, Monty Levin (David Krumholtz). O que há de incomum nesse fato é a posição que Herman passa a ocupar na empresa: em vez de se aproveitar do nepotismo e acatar um cargo executivo, ele passa a atuar na linha de frente com os trabalhadores braçais, carregando sacolas de legumes e dirigindo o caminhão. Em uma cena, vemos o cansaço inicial do homem, que estava 
desacostumado com o esforço físico, mas seu espírito mantémse vigoroso: ele inclusive expressa prazer no exercício e indica que logo criará os músculos necessários ao desempenho da função.

A utopia do trabalho está associada a uma visão antropocêntrica. O trabalho concreto, "vivo", que "se apodera das coisas e desperta-as do mundo dos mortos" (MARX, 2013, p. 260) é o triunfo da vontade humana sobre a natureza: trata-se de agir com vistas às necessidades e aos objetivos socialmente úteis: teleologia. Ao mesmo tempo, também é o trabalho que forma o humano, o que Lukács especifica, com base na obra marxiana, como ontologia do ser social:

O trabalho dá lugar a uma dupla transformação. Por um lado, o próprio ser humano que trabalha é transformado por seu trabalho; ele atua sobre a natureza exterior e modifica, ao mesmo tempo, sua própria natureza, desenvolve "as potências que nela se encontram latentes" e sujeita as forças da natureza "a seu próprio domínio". (LUKÁCS, 2018, p. 286).

Na tradição das utopias e das distopias, um dos exemplos mais nítidos dessa perspectiva está no conto "The Machine Stops" de E. M. Forster (1928), em que o protagonista ganha potência conforme se desprende do conforto proporcionado pelas máquinas que tudo lhe provêm e recupera massa muscular e capacidade cognitiva - de modo similar ao que ocorre com Herman Levin no desempenhar do serviço braçal. Eles rejeitam a facilidade e a mediação das máquinas, a atividade intelectual e o lazer - o mundo percebido da perspectiva do consumo - e tornam-se, carnalmente, produtores de movimento e de sentido. Na utopia fundante de William Morris, News from Nowhere (1908), o trabalho também é central à identidade e ao senso de realização pessoal das personagens. Vale lembrar que Morris era, antes de tudo, um artesão e industrial de sucesso (THOMPSON, 2011) e que News from Nowhere fora uma resposta a uma utopia anterior, de Edward Bellamy (1890), que priorizava o consumo em detrimento do labor (JAMESON, 2005, p. 143; THOMPSON, 2011, p. 542).

Toda a obra de Simon parece ecoar o impulso de Morris. The Wire é, ainda, o exemplo máximo: cada temporada focaliza um ambiente diferente de trabalho, e as personagens são retratadas constantemente no meio do processo laboral, 
desde os estivadores até os professores, ligados pelo trabalho investigativo em equipe. É na profissão e na atividade produtiva que os indivíduos se definem e se valorizam, muitas vezes em detrimento da vida pessoal afetivo-familiar.

Em Carvalho (2018), discutimos com detalhe a obra de Simon em relação aos temas do trabalho, do neoliberalismo e da tradição do drama televisivo contemporâneo. Por isso, refreamo-nos em traçar aqui novamente esses paralelos. É suficiente enfatizar que o trabalho é simultaneamente tema e esquema formal para uma ampla gama de programas que retira das situações laborais sua força motriz. Dramaturgia televisiva necessita de ação, e o ato de trabalhar confere sentido e materializa obstáculos, fato que o predispõe ao gênero. Além disso, o esquema de repetição ajuda na produção de roteiros de séries procedurais, enquanto a variedade dos casos enfrentados por médicos, advogados, jornalistas, assistentes sociais e outros profissionais liberais que protagonizam tais séries garante a novidade.

\section{A utopia da social-democracia}

Em Homicide, The Wire, The Corner e Treme, a esfera política é vista de relance. Com alguns apertos de mão, os acordos entre os poderosos selam propinas e projetos de lei que cascateiam consequências do vértice da pirâmide de poder até a base. $\mathrm{O}$ foco costumeiramente reside nas famílias e nos indivíduos, cujas vidas sofrem os efeitos das decisões políticas. O procedimento é análogo ao descrito por Lukács (1962, p. 15) em respeito ao romance histórico: "a derivação de uma individualidade de personagens a partir da peculiaridade histórica de sua época." Ou seja, evita-se tratar de eventos e acontecimentos reais a partir da perspectiva dos grandes nomes, para criar tipos de personagens cujas ações encarnem o espírito de uma época.

Esse modus operandi se aplica a praticamente todas as séries de David Simon, com menos intensidade em Show me a Hero (2015) e em The Plot Against America. Na primeira série, baseada em fatos reais, acompanhamos o mandato de um jovem prefeito na cidade de Yonkers, Nova York, e seus dilemas durante um impasse relacionado com a aplicação de políticas habitacionais destinadas a enfrentar a segregação 
racial. A série se divide em vários núcleos, que abrangem habitantes negros e brancos da cidade, empreiteiros, juízes e especialistas em moradia, além da família do próprio prefeito. Aqui, a organização balzaquiana dos múltiplos pontos de vista ilumina as pressões econômicas, sociais e pessoais a que estão submetidas todas as partes envolvidas, desde uma viúva, que sai do conjunto habitacional no centro da cidade e consegue uma casa nos subúrbios, até o próprio prefeito, Nick Wasicsko (Oscar Isaac).

A questão utópica do conteúdo poder-se-ia à representação do idealismo de Wasicsko e dos diversos reformadores sociais, que buscam concretizar as mais recentes teorias de planejamento urbano para ajudar as minorias pobres a ascender economicamente por meio de novos paradigmas de habitação, que buscam superar os modelos de grandes conjuntos habitacionais verticais adotando a incorporação de famílias em subúrbios de casas próprias. Contudo, a verdadeira utopia reside no nível próprio do procedimento da série, que vai conectando e explicando, com base na perspectiva multifocal, as consequências de articulações político-econômicas e as transformações ideológicas de cada um dos residentes conforme eles entram em contato com a luta política pró ou contra a reforma urbana.

Essa teia de relações é típica das séries de Simon, que parece tê-la explorado com mais profundidade do que qualquer outro escritor de dramaturgia televisiva até agora. De fato, os laços e as conexões aprofundam-se e ramificam-se em relações causais complexas, que encontram reflexos nas ações e na psicologia de cada um dos personagens. Em séries como Show me a Hero, é possível enxergar com mais nitidez o procedimento como uma metáfora para o ideal social-democrático do liberalismo esclarecido, no sentido que confere e exalta o poder de assembleia, diálogo e deliberação. Personagens entram em contato uns com os outros durante a luta política pelo próprio espaço da cidade e até mesmo mudam de opinião. O único subproduto trágico é o próprio prefeito Wasicsko, que sucumbe ao tentar equilibrar, sozinho, pressões sociais exasperantes.

Também podemos ver nisso um ideal da televisão em geral, especialmente da teledramaturgia de horário nobre, de configurar um "fórum cultural": "[...] uma maneira de compreender quem e o que somos, como os valores e atitudes são 
29 "[...] a way of understanding who and what we are, how values and attitudes are adjusted, how meaning shifts"
30 "As pessoas haviam dito que o rádio criaria um fórum de cidadãos. Isso não aconteceu."

"People had said the radio would create a town meeting, too. It had not." (LEPORE, 2018 p. 543). "[...] malasdiretas e televisão a cabo segmentaram o eleitorado e balcanizaram o público." "[...] direct mail and cable television segmented de electorate and balkanized the public" (LEPORE, 2018, p. 666). O maior marco desse processo está na derrocada da Fairness Doctrine em 1987, quando o governo Reagan decide extinguir a obrigatoriedade de que a programação tivesse relação com os interesses públicos ou que diferentes pontos de vista tivessem espaço igual de deliberação. (LEPORE, 2018, p. 704). ajustados e como o significado muda"29 (NEWCOMB; HIRSCH, 1983, p. 564). Essa é a visão que Newcomb e Hirsch advogam ao perceberem que a televisão se tornara o centro da disputa de valores da sociedade e que, no horário nobre, quando famílias inteiras se reuniam para assistir a determinados programas, havia uma oportunidade para dramatizar e deliberar pontos de vista dissonantes. A possibilidade de se colocar no lugar do outro com narrativas multifocais é vista com esperança pelos críticos, como resultado da ambição democrática de compartilhar e debater experiências individuais e coletivas à luz da neutralidade e da ponderação.

The Plot Against America também traz à luz conexões entre altas esferas políticas e a vida de pessoas comuns. Embora Lindbergh não seja um personagem plenamente desenvolvido, como o prefeito de Show me a Hero, suas deliberações e as de seus representantes em cargos de poder, como o rabino Lionel Bengelsdorf (John Torturro), impactam diretamente a vida de personagens, como o jovem vizinho dos Levin, Seldon Wishnow (Jacob Laval), cuja família é realocada para o Kentucky e morta pela Klu Klux Klan.

Contudo, há uma diferença marcante. A esperança no fórum cultural de Newcomb e Hirsch fazia sentido no final dos anos 1970, quando a televisão nos Estados Unidos e na maior parte do mundo ainda era fortemente centralizada e a programação não passava de um punhado de canais, o chamado modelo de broadcast. Conforme se estabelecem a televisão a cabo, os videocassetes e outros aparelhos reprodutores caseiros, e agora as redes de streaming, a televisão fragmenta-se, e os públicos segmentam-se - o que denominamos narrowcasting (CARVALHO, 2018, p. 51-68; LOTZ, 2014, p. 199). É possível escolher programas específicos e consumi-los como se adquirem revistas e romances. Como vimos, para Lepore, esse processo está em consonância com o aumento da polarização política e do "abismo epistemológico" que separa campos distintos. ${ }^{30} \mathrm{Em}$ The Plot Against America, o problema do narrowcasting parece representado na figura de Walter Winchell, uma personalidade de rádio, cujo programa é seguido assiduamente por Levin. De certa forma, toda a família desconecta-se da realidade, minimizando a ameaça de Lindbergh, justamente porque a visão de mundo de Levin não ultrapassa a bolha ideológica do radialista. Eles, inclusive, perdem a oportunidade de fugir 
31 "a treatise about the death of work" para o Canadá, mesmo após diversos de seus conhecidos tentarem alertá-los para a iminência do perigo. O equivalente simetricamente oposto da situação, atualmente, parecem ser as redes independentes de jornalismo da alt-right, que (des) informam Donald Trump a ponto de termos à impressão de que o ex-presidente e seus seguidores habitam uma realidade paralela, talvez comparável apenas à alienação da metade democrata urbana, que também se fecha em seus próprios programas e bolhas sociais (PARISER, 2011).

\section{A utopia da família}

Para David Simon, a cidade de Baltimore que resta após o processo de desindustrialização já é um cenário distópico de desemprego e de uma juventude sem perspectivas. Segundo o escritor-produtor, a segunda temporada de The Wire e a série como um todo são um "tratado sobre a morte do trabalho" ${ }^{31}$ (SIMON, 2010, p. 11). Na esfera política, como já vimos, a eleição de Trump parece indicar a possibilidade de um segundo tipo de distopia, o esvaziamento do político e o "complô contra a América", o golpe final contra a democracia representativa liberal desferido pelo populismo do líder carismático totalitarista.

Contudo, nas obras de Simon, parece haver contrapontos fundamentais que servem ao mesmo tempo de ponto nodal de explicação, identificação e resistência, como o trabalho, as práticas republicanas da social-democracia (abordados na seção anterior) e a família. Em Homicide, família e trabalho são a mesma coisa. Trata-se da "família do trabalho" que surge na tragicomédia procedural televisiva, a partir dos anos 1970, com a renovação das sitcoms (NEWCOMB, 1974) e, de 1980 em diante, no drama de horário nobre (CARVALHO, 2018). Em The Wire, é representativo o arco narrativo de Namond Brice (Julito McCullum), o filho de um traficante violento, que acaba superando o destino comum de adolescentes das ruas de Baltimore quando, ao final da série, é adotado por um policial aposentado (CARVALHO, 2018, p. 375). Especialmente em Show me a Hero e em The Plot Against America, é a perspectiva familiar que permite aos personagens e aos espectadores situarem-se em meio à disputa política. Na série mais recente, Lindbergh representa uma ameaça à noção do judaísmo como tribo ou 
${ }^{32}$ Uma conexão interessante entre gueto judeu e romance utópico é notada por Claeys (2017, p. 5) quando ele observa a coincidência entre a escrita de Utopia (2016) de Thomas Morus e o surgimento de comunidades judaicas isoladas em Veneza. O caráter necessário do isolamento da sociedade utópica foi apontado por Jameson (2005, p. 5), e percebemos o entrelaçamento entre o isolamento da família nuclear judaica também como uma forma de resistência perante a distopia da realidade alternativa

da presidência de Lindbergh em The

Plot Against America.

A motivação de

Roth ao escrever um romance que ressalta a possibilidade do avanço do antissemitismo nos

Estados Unidos dos anos 1930-1940 está expressa em WirthNesher (2007, p. 167).

Por fim, a avaliação de Parrish (2007, p.

140) corrobora nossa interpretação de que a família, para Roth (assim como para Simon), é vista como refúgio: "O poder do romance reside no retrato comovente que Roth faz de seus pais como o refúgio contra todo o medo." "The novel's power resides in Roths's moving portrait of his parents as a refuge from all fear."

33 "The situation of the family in postFordist capitalism is contradictory, in precisely the way that traditional Marxism expected: capitalism requires the family (as an essential means of reproducing and caring for labor power; as a salve for the psychic wounds inflicted by anarchic socialeconomic conditions), even as it undermines it (denying parents time with children, putting família expandida, com seu programa de fragmentação dos guetos judeu ${ }^{32}$ e incorporação de famílias isoladas no território do interior dos Estados Unidos, e também pela divisão que provoca internamente entre as irmãs Elizabeth Levin (Zoe Kazan) e Evelyn Finkel (Winona Ryder).

Aqui é importante diferenciar entre uma tendência geral conservadora a partir da metade dos anos 1970, que surge como resposta às crises do capitalismo fordista-keynesiano e se expressa na televisão, particularmente no melodrama, e a obra específica de Simon, que utiliza e subverte essa tendência ao ampliar o foco da representação para muito além da domesticidade.

Mark Fisher (2009, p. 32) percebe que:

A situação da família no capitalismo pós-fordista é contraditória, precisamente na forma como o marxismo tradicional esperava: o capitalismo exige a família (como um meio essencial de reprodução e cuidado da força de trabalho; como um bálsamo para as feridas psíquicas infligidas por condições econômicas e sociais anárquicas), mesmo enquanto [o capitalismo] mina [a família] (negando aos pais tempo com crianças, colocando uma tensão intolerável nos casais, conforme eles se tornam a fonte exclusiva de consolo um do outro). ${ }^{33}$

Essa situação desemboca na ascensão de um novo conservadorismo, que atinge o auge durante o governo de Reagan (LEPORE, 2018, p. 630-710) e se expressa, por um lado, em novos ramos da filosofia, como na obra de Christopher Lasch e sua preocupação com a perda da autoridade patriarcal (ARONOWITZ; DIFAZIO, 1994, p. 311; LASCH, 1991); e, por outro, em novos tipos de melodrama televisivo (FEUER, 1994, 1995), que dependem cada vez mais da estabilidade da esfera doméstica como foco de resistência às transformações econômico-sociais. A família torna-se uma utopia, um apanágio contra a desestruturação de redes de proteção social conforme políticas públicas sofrem o desinvestimento das políticas neoliberais. É compreendida como utopia porque a família nuclear idealizada do fordismo é escancaradamente uma fantasia que só pode existir na ficção. ${ }^{34}$

Simon, cujo começo de carreira se encontra precisamente nesse momento mas que chega à televisão no começo dos anos 1990, com Homicide, certamente recebe e prolonga a tradição 
intolerable stress on couples as they become the exclusive source of affective consolation for each other)."

${ }^{34}$ Ryskamp (2020) escreve sobre como uma das famílias mais tradicionais da televisão estadunidense,

The Simpsons, representam um paradigma estranho aos espectadores de hoje já que o programa mostra um pai de família com emprego blue collar estável capaz de sustentar, sem problemas financeiros, uma família que inclui esposa, três filhos pequenos e agregados.

\footnotetext{
35 Em The Plot Against America, as irmãs Finkel e Levin rompem os laços de sangue após o conflito desencadeado pela posição política antagônica. Contudo, o laço que realmente importa é o da família Levin, que repele a cunhada para fora de seu núcleo, afirmandose como locus de valores positivos autênticos.

36 "But much has surveyed the American class landscape over thirty years ago. Job opportunities for the supposedly liberal professions, which were expanding in the sixties, have in some cases, such as journalism, undergone a devastating decline. Other professional jobs have been severely downgraded, as illustrated by the replacement of tenuretrack professors with low-wage "adjuncts." Yet others (doctors and other health workers, lawyers) have been absorbed into large corporations or corporation-like enterprises."
}

que privilegia o núcleo familiar (ou "família do trabalho"). Trata-se de uma convenção particularmente necessária aos dramas serializados, já que a manutenção de um núcleo estável (FEUER, 1986, p. 105) é precondição para o estabelecimento das séries e dos personagens na memória e na vida cotidiana dos espectadores. Simon e a tradição do drama televisivo da $\mathrm{HBO}$ e dos canais de cabo de prestígio que surgem no final do século XX expandem esse horizonte formal ao multiplicar o número de protagonistas e núcleos narrativos, absorvendo e legitimando procedimentos da telenovela (CARVALHO, 2018). Contudo, como foi discutido no exemplo de The Wire e como fica patente em Show me a Hero e em The Plot Against America, ainda é possível perceber algum sentimentalismo nos desenlaces, nas resoluções do tipo "final feliz", que significam frequentemente a reconstituição de uma família nuclear. Como veremos na próxima seção, podemos ler isso como uma manifestação de wish-fullfilment, de utopia no sentido de um retorno a uma época mais feliz, em que relações trabalhistas e familiares supostamente mais estáveis ainda estavam no horizonte de possibilidade do sonho americano..$^{35}$

\section{Horizontes da utopia democrata}

O trabalho de Barbara e John Ehrenreich (2013) explica, como nenhum outro, a degradação do panorama da classe média nos Estados Unidos desde os anos 1970. Ele se concentra especificamente nas fatias de profissionais liberais, como jornalistas, médicos e advogados:

No entanto, muita coisa está diferente desde a época em que pesquisamos o panorama de classe dos Estados Unidos há mais de trinta anos. As oportunidades de emprego para profissões supostamente liberais, que estavam se expandindo nos anos sessenta, em alguns casos, como o jornalismo, sofreram uma baixa devastadora. Outros empregos profissionais experimentaram um severo rebaixamento de nível, como ilustrado pela substituição de professores com estabilidade por "adjuntos" mal remunerados. Ainda outros (médicos, profissionais de saúde e advogados) foram absorvidos por grandes corporações ou por empresas que funcionam como corporações. (EHRENREICH; EHRENREICH, 2013, p. 4) ${ }^{36}$ 
37 "It is made unmistakably clear to the intellectual from abroad that he will have to eradicate himself as an autonomous being if he hopes to achieve anything or be accepted as an employee of the super-trust into which life has condensed. The refractory individual who does not capitulate and completely toe the line is abandoned to the shocks which the world of things, concentrated into gigantic blocks, administers to whatever does not make itself into a thing. Impotent in the machinery of the universally developed commodity relation, which has become the supreme standard, the intellectual reacts to the shock with panic."
A tendência observada é de uma enorme proletarização dessa classe, que perde os privilégios "liberais" de autonomia e/ou passa a viver sob a constante ameaça de redundância ou absorção pela burocracia corporativa. Para nós, são relevantes as implicações subjetivas dessa relativa degradação, o modo como os indivíduos de uma classe antes privilegiada e afluente encaram a vida. Segundo nosso argumento maior, o prisma dessa perspectiva condiciona diretamente a produção artística e intelectual, além da atuação política individual.

Notemos que essa não é uma situação única. Há paralelos em épocas relativamente recentes: sempre que a classe de profissionais liberais é frustrada em suas aspirações - não importa se baseadas no egoísmo do privilégio ou no altruísmo da disseminação da igualdade e da justiça social -, percebemos consequências imediatas na arte, como a adoção de posturas extremadas que contrapõem radicalmente indivíduo e sociedade, utopia e distopia, trabalho pleno de sentido e consumo de massa etc. Williams Morris, por exemplo, estaria situado num momento de significante frustração tanto em relação ao valor do trabalho manual-artesanal como fonte de identidade, quanto à possibilidade de organização política anticapitalista. News from Nowhere, nas primeiras páginas, parte das dificuldades de concretização do socialismo e baseia-se inteiramente em uma sociedade repleta de artesãos-autônomos.

Em um momento posterior, Adorno, ao comentar Brave New World, compõe um retrato do intelectual que se assemelha à descrição dos Ehrenreich referida anteriormente:

\begin{abstract}
Sem sombras de dúvidas, fica claro para o intelectual que vem de fora que ele terá que apagar seus traços de ser autônomo, caso ele espere alcançar qualquer coisa ou ser aceito como um funcionário do supertruste em que a vida se condensou. O indivíduo refratário que não capitula e se conforma completamente fica abandonado aos choques com que o mundo das coisas, concentrado em blocos gigantescos, aplica em tudo que não se transforma em coisa. Impotente na maquinaria da universalmente desenvolvida relação-mercadoria, que se tornou o padrão supremo, o intelectual reage ao choque com pânico. ${ }^{37}$ (ADORNO, T. W., 1997, p. 97, grifos nossos)
\end{abstract}

O intelectual, o profissional liberal ou o artista, sejam Morris, Huxley ou Simon, confronta-se com a degradação de sua classe e de seus valores. $\mathrm{O}$ inimigo tem diversos nomes - 
"rebaixamento de nível", "grandes corporações", "supertrustes", "relação-mercadoria" -, mas o efeito é o mesmo: a sensação de perda de autonomia. A resposta é estética, e aqui podemos enquadrar também a reação conservadora do modernismo anglo-saxão, que eleva a figura do poeta justamente no momento em que o trabalhador intelectual se vê desesperado frente ao "massivo" e ao "comercial" (CAREY, 2002). Nesse momento, utopias e distopias sedimentam-se num gênero próprio, em que as visões de céu e inferno confrontam-se no plano do assunto e ligam-se à imaginação das consequências de progressos científicos e de experimentos sociais, que participam também daquilo que estamos resgatando com o nome de elementos utópicos e distópicos presentes em obras que não se conectam diretamente à fantasia e à ficção científica, como as séries de Simon anteriores a The Plot Against America. É possível afirmar que a desolação de Baltimore em The Wire, os centros urbanos dos anos 1970-1980 e os conjuntos habitacionais de Show me a Hero são essencialmente distópicos; enquanto a família do trabalho em Homicide, The Wire e The Deuce, a amizade e a camaradagem no exército de Generation Kill e as famílias estendidas em Treme e em Show me a Hero são essencialmente utópicas. Em The Plot Against America, esses impulsos organizam o plano do assunto propriamente dito com a representação de uma realidade alternativa distópica, ainda que breve. É com da perspectiva relativa do intelectual (ou profissional liberal) que finalmente podemos compreender a gênese e os limites dos elementos utópicos presentes na obra de Simon.

Como vimos, o trabalho é provedouro de orgulho e

38 Se o leitor notar alguma contradição entre a representação positiva do trabalho braçal, como discutido anteriormente a respeito de The Plot Against America e nossa descrição da primazia da perspectiva do trabalhador autônomo/ liberal, resta lembrar que a idealização do esforço físico é frequentemente uma característica do intelectual, que pode encarar o movimento e o esforço como passatempo ou esporte. hecimento. A investigação policial e a astúcia no comércio de drogas, o trabalho artístico e militar e até o trabalho com a pornografia são vistos como fonte de realização humana ao se aproximarem do caráter artesanal que permite plena autonomia aos indivíduos trabalhadores. ${ }^{38}$ As ameaças são representações da burocracia e do corporativismo, como nas figuras de policiais/oficiais, frequentemente gerentes carreiristas que desprezam o esforço individual em nome da mera aparência de produtividade. É um clichê da televisão a figura do chefe boçal conformado à posição de burocrata que deve ser desafiado pelo intrépido protagonista para se chegar à conclusão de um caso. 
39 Em Carvalho (2018), ressaltamos a importância de diretoras e colaboradoras mulheres em The

Deuce.
A própria amplitude dos diversos núcleos dramáticos, bem como a representação direta do universo político, como na terceira temporada de The Wire, em Show me a Hero e em The Plot Against America, figuram um ideal de democracia esclarecida intelectualizada em que argumentos conflitantes podem ser debatidos racional e ponderadamente. É a capacidade intelectual da investigação e a representação linguística extensiva e detalhada dos pontos de vista distintos que vencem a irracionalidade da motivação do lucro (The Wire, Treme, The Deuce) e do ódio ao diferente (Generation Kill, Show me a Hero, The Plot Against America).

Por último, a família aparece como refúgio e contrapeso da racionalidade trabalhadora, o espaço onde é possível viver o plano emocional rejeitado pela esfera pública. Aqui, obviamente, surge uma divisão de trabalho com tons machistas e patriarcais, que está presente em Simon ao questionarmos a variedade de temas e protagonistas de suas séries: o mundo do crime, do exército e da política controlado por homens - com a significativa exceção de The Deuce. ${ }^{39}$

Neste ponto, já podemos abandonar as definições de utopia e distopia que se pretendem universais e abstratas, como aquelas discutidas nas primeiras seções. Distopias não são, essencialmente, conformistas. Também não levam, necessariamente, à tomada de consciência e à ação política eficazes. Elas advêm de perspectivas de classe específicas e, como tal, apresentam funções relativas e limites compartilhados com o campo mais geral do qual fazem parte. Cada um dos elementos analisados na obra de Simon tem lugar no discurso amplo de uma fatia intelectual-liberal do campo progressista estadunidense, que volta ao poder com a eleição de Joe Biden e Kamala Harris. O discurso da vice-presidenta eleita e as breves distopias de Simon constroem suas visões apocalípticas e sugerem soluções que, não por coincidência, correspondem aos valores dessa classe.

Ao identificarmos e analisarmos esses valores em relação à categoria de classe, reconquistamos a capacidade de apontar também seus limites. O retorno ao trabalho plenamente autônomo e seguro do período fordista, a social-democracia ponderada e a família estável parecem, mais do que nunca, ideais que se concretizaram apenas em breves períodos para privilegiadas fatias da sociedade de poucos países. 
40 "Estou à esquerda do Partido Democrata em três quartos de qualquer assunto que você possa imaginar. Provavelmente estou à esquerda de qualquer um dos candidatos indicados para já concorrerem às eleições gerais." "I'm on the left of the Democratic party on three-quarters of the issues you could imagine. I'm probably to the left of every single general election nominee the Democrats have ever offered." (SIMON, 2020c, n. p.)

41 "false reconciliation"

42 "In art, unreconciled reality tolerates no reconciliation with the object; realism which does not reach the level of subjective experience, to say nothing of reaching further, merely mimics reconciliation."
Portanto, a defesa desses valores vem soando como nostalgia, essencialmente um erro de avaliação que considera tais valores como universais e não como exceções insustentáveis dentro do regime capitalista. Embora se afirme "mais à esquerda" do que o Partido Democrata, ${ }^{40}$ seria impensável que The Wire fosse a série preferida de Barack Obama (WEISBERG, 2006), a menos que ela conseguisse contornar uma posição verdadeiramente radical. O sucesso das séries de Simon e seu apoio incondicional pelo canal de televisão a cabo de maior prestígio por fatias urbanas progressistas norte-americanas dão-se justamente pela ausência de críticas contumazes ao capitalismo e por seu apoio a ideais que, conforme mostramos, coadunam-se com o próprio formato do drama televisivo desde 1970 e com seus modos de acomodação das contradições econômico-sociais: como salienta Michael Newman (2006, p. 17), a televisão acaba sendo "gratificante, não desafiadora" e seu realismo, conforme a expressão de Adorno (1991, p. 77), é "falsa reconciliação"41. Assim também foi o discurso de Harris, que poderia ser resumido com um pragmático let's get back to business (vamos voltar aos negócios).

Propomos, por último, que a noção de distopia deva ser levada aos extremos. Contra Lepore (2017), não concordamos que o problema das distopias contemporâneas seja o excesso de negatividade, que supostamente aumenta o abismo cognitivo entre universos políticos antagônicos, mas, pelo contrário, que essas obras não são negativas o suficiente, já que deixam espaço para as formas de reconciliação: seja com o leitor, na forma de um realismo pedestre, seja com perspectivas tão privilegiadas quanto ultrapassadas. Aqui, lembramos da análise de Adorno (1982, p. 127) acerca de uma das maiores obras distópicas do teatro, Endgame, de Samuel Beckett: “Na arte, a realidade não conciliada não tolera a reconciliação com o objeto; o realismo que não chega ao nível da experiência subjetiva, sem falar da ambição de ir além disso, simplesmente faz a mímica da reconciliação" ${ }^{\prime 2}$. O sinal de advertência que as distopias supostamente trazem deve soar tão agudo quanto a potência desumanizadora do capitalismo tardio, ou tão grave. 


\section{REFERÊNCIAS}

ADORNO, T. The Schema of Mass Culture. In: Bernstein, J. M. (Ed.). The Culture Industry: Selected Essays on Mass Culture. New York: Routledge, 1991. p. 61-97.

ADORNO, T. W. Aldous Huxley and Utopia. In: . Prisms. Tradução de Samuel Weber e Shierry Weber. Cambridge, MA: The MIT Press, 1997. p. 95-118.

. Trying to Understand Endgame. New German Critique, Durham, n. 26 (Summer), p. 119-150, 1982.

ARONOWITZ, S.; DIFAZIO, W. The Jobless Future. Minneapolis: University of Minnesota Press, 1994.

ATWOOD, M. The Handmaid's Tale. New York: Houghton Mifflin Harcourt, 1986.

BELLAMY, E. Looking Backward: 2000-1887. Chicago: F. J. Schulte \& Co, 1890.

BLOCH, E. (1959) O princípio esperança. v. 1. Tradução de Nélio Schneider. Rio de Janeiro: Contraponto, 2005.

CAREY, J. The Intellectuals and the Masses: Pride and Prejudice Among the Literary Intelligentsia, 1880-1939. Chicago: Chicago Review Press, 2002.

CARVALHO, A. F. G. Representação do trabalho e trabalho de representação em narrativas seriadas televisivas norte-americanas. 2018. 423 f. Tese (Doutorado em Letras) - Instituto de Biociências, Letras e Ciências Exatas - Universidade Estadual Paulista, São José do Rio Preto, 2018.

CLAEYS, G. Dystopia: A Natural History: A Study of Modern Despotism, Its Antecedents, and Its Literary Diffractions. Oxford: Oxford University Press, 2017.

EHRENREICH, B.; EHRENREICH, J. Death of a Yuppie Dream: The Rise and Fall of the Professional-Managerial Class. New York: Rosa Luxemburg Stiftung, 2013. Disponível em: http:// www.rosalux-nyc.org/death-of-a-yuppie-dream. Acesso em: 12 maio 2016. 
FEUER, J. Melodrama, Serial Form and Television Today. In: Newcomb, H. (Ed.). Television: The Critical View. 5. ed. Oxford: Oxford University Press, 1994.

. Narrative Form in American Network Television. In: Maccabe, C. (Ed.). High Theory/Low Culture. Manchester: Manchester University Press, 1986.

Seeing through the Eighties: Television and Reaganism. Durham: Duke University Press, 1995.

FISHER, M. Capitalist Realism: Is There No Alternative? Winchester: Zero Books, 2009.

FORSTER, E. M. The Machine Stops. In: The Machine Stops and Other Stories. London: Sidgwick \& Johnson, 1928.

FORSTER, E. M. What I Believe. In: . Two Cheers for Democracy. New York: Harcourt, Brace \& Co, 1966. p. 67-76.

FREEDMAN, C. Critical Theory and Science Fiction. Hanover, NH: Wesleyan University Press, 2000.

GENERATION Kill. Criação: David Simon. EUA: HBO. 2008. Minissérie em 7 episódios.

HARRIS, K. Kamala Harris's historic victory speech in full: "You chose truth". YouTube, London, 7 nov. 2020. Guardian News. Disponível em: https://www.youtube.com/ watch?v=MXnePLTILY4. Acesso em: 8 nov. 2020.

HOMICIDE: Life on the Street. Criação: Paul Attanasio. EUA: NBC. 1993. Série em 7 temporadas (1993-1999).

HUXLEY, A. Brave New World. London: Chatto \& Windus, 1947.

JAMESON, F. Archaeologies of the Future: The Desire Called Utopia and Other Science Fictions. London: Verso, 2005.

. Realism and Utopia in "The Wire". In: The Acients and The Postmderns: On the Historicity of Forms. London: Verso Books, 2015. p. 239-254. 
LASCH, C. The Socialization of Reproduction and the Collapse of Authority. In: The Culture of Narcissism: American Life in an Age of Diminishing Expectations. New York: W.W. Norton \& Co., 1991.

LE GUIN, U. K. (1974) The Dispossessed: An Ambiguous Utopia. New York: HarperCollins, 2009.

LEPORE, J. A Golden Age for Dystopian Fiction. The New Yorker, New York, 12 jun. 2017. Books. Disponível em: https:// www.newyorker.com/magazine/2017/06/05/a-golden-age-fordystopian-fiction. Acesso em: 10 out. 2020.

. These Truths: A History of the United States. New York: W. W. Norton, 2018.

LOTZ, A. The Television Will Be Revolutionized. New York: New York University Press, 2014.

LUKÁCS, G. Para uma ontologia do ser social. v. 1. Tradução de Carlos Nelson Coutinho e Mario Duayer e Nélio Schneider. São Paulo: Boitempo, 2018.

The Classical Form of the Historical Novel. In:

The Historical Novel. Tradução de Hannah Mitchell e Stuart Mitchell. London: Merlin Press, 1962.

MARX, K. O capital: crítica da economia política: o processo de produção do capital. v. 1. Tradução de Rubens Enderle. São Paulo: Boitempo, 2013.

MILNER, A. J. Locating Science Fiction. Liverpool: Liverpool University Press, 2012.

MORRIS, W. News from Nowhere. London: Longmans, Green, and Co., 1908.

MORUS, T. (1516) Utopia. 4. ed. Tradução de Aires A. Nascimento. Lisboa: Fundação Carlos Gulbenkian, 2016.

MOYLAN, T. Demand the Impossible: Science Fiction and the Utopian Imagination. Bern: Peter Lang, 2014. 
Scraps Of The Untainted Sky: Science Fiction, Utopia, Dystopia. Wesport: Westview Press, 2000.

NEWCOMB, H. Situation and Domestic Comedies: Problems, Families, and Fathers. In: TV: The Most Popular Art. Garden City, NY: Anchor P, 1974.

NEWCOMB, H.; HIRSCH, P. Television as a Cultural Forum: Implications for Research. Quarterly Review of Film Studies, London, v. 8, n. 2, p. 43-55, 1983.

NEWMAN, M. Z. From Beats to Arcs: Toward a Poetics of Television Narrative. The Velvet Light Trap, Madison, v. 58, n. Fall, p. 16-28, 2006.

ORWELL, G. (1949) 1984. New York: Houghton Mifflin Harcourt Publishing, 1987.

Letter to Francis A. Henson (extract). In: The Collected Essays, Journalism, and Letters of George Orwell: In front of your nose, 1945-1950. v. 4. London: Harcourt, Brace \& World, 1968. p. 502.

Politics vs. Literature: An Examination of Gulliver's

Travels. In: . Shooting an Elephant. London: Penguin Books, 2003a.

The Prevention of Literature. In: Shooting an Elephant. London: Penguin Books, 2003b.

PARISER, E. The Filter Bubble: What the Internet is Hiding from You. New York: Penguin Press, 2011.

PARRISH, T. Roth and ethnic identity. In: Parrish, T. (Ed.). The Cambridge Companion to Philip Roth. Cambridge: Cambridge University Press, 2007. p. 127-141.

ROTH, P. The Plot Against America. New York: Vintage, 2005.

SARGENT, L. T. The Three Faces of Utopianism Revisited. Utopian Studies, University Park, v. 5, n. 1, p. 1-37, 1994.

. Utopianism: A Very Short Introduction. Oxford: Oxford University Press, 2010. 
SHOW Me a Hero. Criação: David Simon; William F. Zorzi. EUA: HBO. 2015. Minissérie em 6 episódios.

SIMON, D. David Simon on the End of The Plot Against America (and Democracy). Entrevista por Kathryn VanArendonk. Vulture, Washington, D. C., 20 abr. 2020a. Disponível em: https://www.vulture.com/2020/04/david-simon-plot-againstamerica-finale.html. Acesso em: 20 nov. 2020.

. David Simon on the Timely Terrors of His New HBO Series "The Plot Against America". Entrevista por Christina Radish. Collider, [S. 1.], 16 mar. 2020b. TV. Disponível em: https:// collider.com/david-simon-interview-the-plot-against-america/. Acesso em: 20 nov. 2020.

. David Simon: "There's Nothing to Do but Have the Fight". Entrevista por Alex Bilmes. Esquire, [S. 1.], 11 jul. 2020c. TV. Disponível em: https://www.vanityfair.com/ hollywood/2020/04/david-simon-the-wire-plot-againstamerica-interview. Acesso em: 20 nov. 2020.

Picador, 1991.

Homicide: A Year on the Killing Streets. New York: Introduction by David Simon. In: Alvarez, R. (Ed.). The Wire: Truth Be Told. New York: Grove Press, 2010.

The Wire Forever: David Simon on the Quarantine Favorite and His Equally Pissed-Off New Show, The Plot Against America. Entrevista por Maureen Ryan. Vanity Fair, New York, 17 abr. 2020d. TV. Disponível em: https://www. vanityfair.com/hollywood/2020/04/david-simon-the-wireplot-against-america-interview. Acesso em: 20 nov. 2020.

SIMON, D.; BURNS, E. The Corner: A Year in the Life of an Inner-City Neighborhood. New York: Broadway Books, 1998.

SUVIN, D. (Ed.). Defined by a Hollow. Essays on Utopia, Science Fiction and Political Epistemology. Bern: Peter Lang, 2010.

Metamorphoses of Science Fiction: On the Poetics and History of a Literary Genre. New Haven: Yale University Press, 1977. 
THE CORNER. Criação: David Simon; David Mills. EUA: HBO. 2000. Minissérie em 6 episódios.

THE DEUCE. Criação: David Simon; George Pelecanos. EUA: HBO. 2017. Série em 3 temporadas (2017-2019).

THE PLOT Against America. Criação: David Simon; Ed Burns. EUA: HBO. 2020. Minissérie em 6 episódios.

THE WIRE. Criação: David Simon. EUA: HBO. 2002. Série em 5 temporadas (2002-2008).

THOMPSON, E. P. William Morris. Oakland: PM Press, 2011.

TREME. Criação: Eric Ellis Overmyer; David Simon. EUA: HBO. 2010. Série em 4 temporadas (2010-2013).

VONNEGUT, K. Player Piano. New York: The Dial Press, 1952.

WALLACE, M. The American Axis: Henry Ford, Charles Lindbergh, and the Rise of the Third Reich. New York: St. Martin's Press, 2003.

WEGNER, P. E. Preface: Emerging from the Flood in Which We Are Sinking: Or, Reading with Darko Suvin (Again). In: Suvin, D. (Ed.). Defined by a Hollow: Essays on Utopia, Science Fiction and Political Epistemology. Bern: Peter Lang, 2010. p. xv-xxxiii.

WEISBERG, J. "The Wire" on Fire. Slate, Arlington County, 13 set. 2006. Disponível em: http://www.slate.com/articles/ news_and_politics/the_big_idea/2006/09/the_wire_on_fire. html. Acesso em: 17 abr. 2018.

WILLIAMS, L. Ethnographic Imaginary: The Genesis and Genius of The Wire. Critical Inquiry, Chicago, v. 38, n. 1, p. 208226, 2011. Disponível em: https://www.journals.uchicago.edu/ doi/abs/10.1086/661650. Acesso em: 25 maio. 2016.

WILLIAMS, R. George Orwell. In: Culture and Society, 1780-1950. New York: Columbia University Press, 1983. p. 285294. 
. Tenses of Imagination: Raymond Williams on Science Fiction, Utopia and Dystopia. Bern: Peter Lang, 2010.

Utopia and Science Fiction. Science Fiction Studies, Greencastle, v. 5, n. 3, p. 203-214, nov. 1978.

WIRTH-NESHER, H. Roth's autobiographical writings. In: Parrish, T. (Ed.). The Cambridge Companion to Philip Roth. Cambridge: Cambridge University Press, 2007. p. 158-172.

Dystopia and Utopia in the Work of David Simon: a Reading of The Plot Against America

\section{ABSTRACT}

The main objective of this article is to discuss the dystopian and utopian elements present in multiple television series written or produced by David Simon, such as The Wire and Show me a Hero, with special attention to the analysis of The Plot Against America, a recent adaptation by David Simon and Ed Burns from Philip Roth's eponymous novel, which tells an "alternative story" where the United States elects Charles Lindbergh as president and ally with Axis forces in World War II. First, we establish the centrality of the concept of dystopia in the contemporary political debate since the election of Donald Trump in 2016. We identify that the term emerges subliminally in the victory speech of elected vice president, Kamala Harris, representing the trend pointed out by Jill Lepore of increasing political polarization. Then, we examine the ongoing discussions around dystopia, which will help us to specify in David Simon's other series the utopian elements, whose thematic and formal boundaries prove to be exemplary of a political class aligned with the Democratic Party. We argue that Simon relies on a utopia of work, 
social democracy and family, and that each of these elements is linked both to the conventions of the format of the contemporary dramatic television series and to the political transformations of the post-Fordist and neoliberal period since the latter 1970s.

Keywords: Dystopia. Utopia. Television. Literature. Democracy.

André Carvalho é mestre em Estudos Linguísticos e Literários em Inglês pela USP e doutor em Letras pela UNESP/ Rio Preto. Sua tese sobre a representação do trabalho na televisão ganhou menção honrosa no prêmio CAPES de teses em 2019. Atualmente, realiza estágio pós-doutoral no Programa de Pós-Graduação em Inglês na UFSC e professor substituto no Departamento de Línguas Estrangeiras Modernas da UFPR. 
